\title{
Peningkatan potensi desa wisata melalui pengembangan kemasan oleh-oleh
}

\author{
Aniek Rumijati ${ }^{1}$, Nurul Asfiah ${ }^{2 \star}$, Yulist Rima Fiandari ${ }^{3}$ \\ ${ }^{1}$ Universitas Muhammadiyah Malang, Indonesia, email: aniekrumijati@gmail.com \\ ${ }^{2}$ Universitas Muhammadiyah Malang, Indonesia, email: asfiah@umm.ac.id \\ ${ }^{3}$ Universitas Muhammadiyah Malang, Indonesia, email: yulist_rima@umm.ac.id \\ *Koresponden penulis
}

\section{Info Artikel}

Diajukan: 31 Okt 2020

Diterima: 30 Jan 2021

Diterbitkan: 16 Feb 2021

Keywords:

gift packaging; safe, easy; environmentally friendly

Kata Kunci:

pengemasan oleh-oleh; aman; mudah; ramah

lingkungan

\section{Lisensi:}

cc-by-sa

\begin{abstract}
The development of Café Sawah as Village Tourism in Pujon Kidul is very important because it has an impact on improving the community's economy. So far, various dairy products by MSEs that are fostered by 'Aisyiyah are sticks and crackers as typical souvenirs from Pujon Kidul Tourism. The souvenirs are still not packaged attractively. Product packaging is an effective marketing strategy in managing the end of production, until it is accepted by the end consumers. As a tourist area that is crowded with visitors, good and effective processing of souvenirs is a solution that can be offered to visitors as souvenirs. The purpose of this community service is to improve good packaging, elegant design, easy to carry and able to maintain the quality of the product during the trip. This community service methods are observation, audience and active participation, in order to increase the value of souvenir products with more attractive packaging, safe and comfortable, with local wisdom. The result of this community service is packaging that has an attractive design, an elegant impression of the product, improving of the product values, and so, it becomes a promotional medium when it is brought to a new place as a souvenir, and then, it will subsequently have impact on increasing the welfare of the surrounding community, especially MSEs fostered by 'Aisyiyah.
\end{abstract}

\begin{abstract}
Abstrak
Pengembangan Café Sawah sebagai Wisata Desa di Pujon Kidul sangat penting dilakukan karena berdampak bagi peningkatan perekonomian masyarakat. Selama ini, produk olahan susu yang dihasilkan oleh UMK berupa aneka stik dan kerupuk sebagai oleh-oleh khas dari Wisata Pujon Kidul masih belum dikemas secara menarik. Kemasan produk menjadi strategi marketing yang jitu dalam pengelolaan akhir produksi, untuk sampai ke tangan konsumen. Sebagai daerah wisata yang ramai dikunjungi, pengolahan oleh-oleh secara baik dan efektif merupakan solusi yang dapat ditawarkan pada pengunjung sebagai buah tangan. Tujuan dari pengabdian ini adalah meningkatkan kemasan produk yang baik, desain yang elegan, mudah dibawa dan mampu mempertahankan kualitas produk yang telah dibeli. Metode pengabdian masayarakat ini adalah observasi, audiensi dan partisipasi aktif, dalam rangka meningkatkan nilai produk oleh-oleh dengan kemasan yang lebih menarik aman dan nyaman, serta memiliki ciri khas daerah (local wisdom). Hasil dari pengabdian masyarakat ini berupa kemasan yang memiliki desain yang menarik, kesan produk yang elegan, peningkatan nilai produk, sehingga menjadi sarana promosi ketika dibawa ke tempat baru sebagai oleh-
\end{abstract}


oleh, selanjutnya hal ini akan berdampak pada peningkatan

kesejahteraan masyarakat sekitar, khususnya UMK binaan 'Aisyiyah.

\section{PENDAHULUAN}

Desa wisata di Indonesia saat ini mengalami perkembangan yang cukup pesat, setelah didukung dengan Dana Desa yang bersumber dari APBN (Peraturan Pemerintah 60 Tahun 2014 tentang Dana Desa, 2014), dan diperjelas oleh Kemenkeu (Buku Pintar Dana Desa, 2017). Data Biro Pusat Statistik (BPS) mencatat ada 1302 desa wisata pada tahun 2014, dan jumlah tersebut mengalami peningkatan hingga mencapai 1734 desa wisata pada tahun 2018 (Wisata, n.d.) sebagaimana Infopublik, 2018. Dana Desa pada dasarnya untuk meningkatkan kesejahteraan masyarakat, dengan menciptakan lapangan kerja, 2) mengatasi kesenjangan, dan 3) mengentaskan kemiskinan. Dalam penggunaannya, Dana Desa merupakan kewenangan dari Desa, bersifat partisipatif dan melalui swakelola yang berbasis sumber daya desa dimanfaatkan sesuai dengan typology desa. Oleh karena itu sejak tahun 2015 mulai banyak bermunculan wisata desa yang mengeksplorasi alam desa, termasuk Wisata Pujon Kidul dan tidak jauh dari area wisata Batu dan sekitarnya.

Daerah Malang Raya dikenal memiliki banyak area wisata yang sangat menarik, khususnya wisata alamnya, baik berupa area pegunungan, pantai, wisata petik buah dan outbond, wisata rafting, maupun daerah kumuh yang disulap menjadi obyek wisata menarik, dan masih banyak lagi pilihan wisata yang lain. Desa wisata Pujon Kidul terletak di Kabupaten Malang, yang juga dikenal dengan nama Wisata Café Sawah (Kidul, n.d.) sebagaimana pada laman https://www.sie.pujonkidul.desa.id/. Tujuan pendirian wisata Café Sawah Pujon Kidul, adalah untuk meningkatkan kesejahteraan masyarakat dengan memberdayakan masyarakat di daerah sekitarnya, dengan mengeksplorasi kekayaan alam area Pujon Kidul sesuai dengan typology daerah tersebut. Secara umum area Pujon Kidul adalah daerah pertanian yang subur, didukung dengan peternakan sapi. Namun sebagaimana desa pada umumnya, Pujon Kidul juga banyak ditinggalkan oleh penduduk yang usia produktif untuk mencari kerja di kota. Namun disisi lain, penduduk yang ada, khususnya pemuda tidak terampil bekerja di sektor pertanian/peternakan tersebut, sebagaimana disampaikan bu Musofah, sebagai sesepuh dan Kader Desa.

Awal Desember 2016, Desa Pujon Kidul bersama 21 desa di seluruh Indonesia, ditunjuk sebagai Desa Program Kampung Iklim (Proklim) Nasional oleh Kementerian Lingkungan Hidup dan Kehutanan. Hal ini dikarenakan desa ini memiliki sejumlah aktivitas warga yang produktif, yang sifatnya terkonsentrasi, (Kidul, n.d.). Berdasarkan hasil wawancara awal dengan mitra dijelaskan, bahwa Aparat Desa mengelompokkan Dusun berdasarkan aktivitas usaha pada perah susu sapi, sehingga disebut kampung susu. Sedangkan kelompok Dusun yang lain diminta warganya untuk mengembangkan tanaman hortikultura. Sumber daya alam yang melimpah, dengan pemandangan gunung yang sangat indah, adalah potensi alam 
menginspirasi Kepala Desa untuk menggerakkan pembangunan dengan Dana Desa. Dengan kekayaan alam yang luar biasa dan melibatkan BUMD, serta Karang Taruna dan Kelompok Sadar Wisata (POKDARWIS), maka diwujudkan Desa Wisata dengan memanfaatkan tanah bengkok desa, (Vicki, 2019). Pemeberdayaan masyarakat ini dengan mengutamakan rasa keadilan, diwujudkan dalam bentuk partisipasi masyarakat yang dalam pelaksanaan harus memberi manfaat yang sebesar-besarnya (Sururi, 2015; Lestari \& Sunarti, 2019).

Saat ini Wisata Café Sawah sudah sangat berkembang, dan sebagai destinasi yang popular didatangi, baik oleh wisatawan di sekitar Malang dan Jawa Timur, maupun wisatawan asing. Meningkatnya jumlah wisatawan ini didukung oleh pengembangan spot wisata maupun berbagai jasa yang dibutuhkan. Dengan meningkatnya jumlah wisatawan, maka pengelola Wisata Café Sawah, juga perlu meningkatkan pengelolaan jasa wisata ini secara lebih detil, teliti dan lebih baik, dengan strategi untuk meningkatkan penjualan hasil panen para petani dengan pengolahan pada hasil panen (Purbaya, 2016). Sebagai destinasi wisata yang telah menjadi ciri khas suatu daerah, maka diperlukan ketersediaan oleh-oleh khas daerah tersebut, yang dikenal dengan penghasil susu maka masyarakat diberdayakan untuk membuat olahan susu.

Pengolahan hasil panen memiliki peranan penting dalam upaya meningkatkan nilai tambah pada suatu komoditas pertanian (Mayrowani, 2013). Wisata Café Sawah saat ini telah memiliki hasil pertanian yang layak untuk menjadi oleh-oleh bagi wisatawan, selain itu juga memiliki aneka olahan susu. Produk oleh-oleh ini seperti yoghurt, minuman susu kemasan, dan aneka olahan kering seperti keripik, kerupuk dan aneka stik. Makanan lokal yang akan memperkaya kekayaan kuliner Indonesia (Tyas, 2017). Makanan merupakan bagian dari budaya lokal yang dapat dikonsumsi dan dapat dipromosikan, memiliki nilai berkontribusi pada ekonomi pengembangan suatu destinasi pariwisata (Bernardo \& Rodrigues, 2020). Oleh-oleh dibeli karena memiliki kualitas produk yang baik dan memuat nilai local (Hartanti et al., 2020).

Oleh-oleh tersebut merupakan produk olahan yang dihasilkan oleh UMK yang disiapkan oleh Desa untuk memenuhi kebutuhan oleh-oleh wisatawan. UMK dari kelompok 'Aisyiyah ini memiliki berbagai produk olahan susu (seperti krupuk susu, stik susu, sabun, permen susu), serta jahe bubuk dan lain-lain, yang telah memiliki Produk Industri Rumah Tangga (PIRT). Kemasan produk adalah faktor pendukung keberhasilan proses produksi, (Gema et al., 2018), yaitu 1) Desain yang memenuhi standar kepuasan klien dan menarik, 2) Performa kemasan produk klien meningkat, 3) Hasil produksi kemasan berfungsi maksimal sebagai pelindung produk, 4) Hasil cetak produksi kemasan sesuai bentuk, ukuran, bahan, serta warna yang sesuai konsep, 5) Kemasan produk klien mampu bersaing dengan produk lain di pasar, dan 6) Citra dan penjualan produk klien meningkat. Saat ini produk tersebut dijual secara eceran, hanya di taruh di kios yang disediakan oleh Pengelola Wisata Café Sawah, namun belum dikemas secara memadai untuk 
bisa menjadi oleh-oleh. Kemasan oleh-oleh menekankan keunikan dan afiliasi lokal (Huang et al., 2020). Oleh-oleh berfungsi juga sebagai sarana promosi suatu tujuan wisata. Oleh-oleh dapat meningkatkan kesadaran wisatawan pada daya tarik objek wisata sekaligus memelihara citra wisata yang dibentuk (Dumbrovská \& Fialová, 2020). Dengan peningkatan kualitas melalui kemasan ini akan meningkatkan nilai jual produk, yang pada ahirnya akan berdampak pada peningkatan profitabilitas produksi, yang sejalan dengan hasil penelitian, bahwa terdapat pengaruh yang signifikan antara biaya kualitas terhadap tingkat profitabilitas perusahaan (Tandiontong et al., 2010).

Kegiatan Pengabdian ini telah melakukan deteksi terhadap aktivitas ketersediaan oleh-oleh dari Wisata Café Sawah pada UMK Binaan 'Aisyiyah, mengingat pemberdayaan perempuan mampu meningkatkan ekonomi keluarga dan desa (Purwantara et al., 2019). Produk olahan susu yang berupa kerupuk susu, stik susu, namun mudah remuk jika tidak dikemas dengan baik. Hal ini menjadi perhatian khusus mengingat oleh-oleh dibeli secara khusus oleh wisatawan ditujukan sebagai buah tangan sebagai penyenang baik untuk keluarga dekat maupun kolega. Oleh karena itu dibutuhkan kemasan yang baik, terlihat elegan, mudah dibawa dan mampu mempertahankan kualitas produk yang telah dibeli (Lemy et al., 2019). Kemasan yang menarik dapat menarik konsumen untuk melakukan pembelian (Dharmeria, 2014; Adiyanto et al., 2019). Desain kemasan memperhatikan unsur estetika yang mengandung informasi dan fakta produk (Mufreni, 2016). Kemasan yang baik mempunyai nilai fungsional dan mengirimkan respon positif bagi konsumen (Apriyanti, 2018). Dan saat ini tuntutan dari kemasan oleh-oleh, adalah hendaknya menggunakan bahan yang ramah lingkungan. Dengan demikian pengabdian masyarakat ini penting dilakukan, untuk meningkatkan potensi wisata melalui pengembangan kemasan produk oleh-oleh.

\section{METODE PELAKSANAAN}

Pengabdian masyarakat di lokasi Wisata Café Sawah Pujon Kidul ini dilakukan dengan melakukan observasi awal dan dilanjutkan dengan audiensi, guna mengidentifikasi kebutuhan dan manfaat dari kegiatan pengabdian yang dilakukan. Pada tahap ini ditemukan masalah tentang oleh-oleh wisata yang belum dikemas dengan baik.

Pelaksanaan Pengabdian ini dilakukan dengan pendekatan Partisipatif, yang berorientasi kepada upaya peningkatan peran serta mitra secara langsung dalam berbagai proses dalam pelaksanaan pengabdian. Berdasarkan hasil observasi dan wawancara maka dibuat rancangan (design) kemasan oleh-oleh Wisata Café Pujon Kidul. Dengan pertemuan melalui zoom meeting, maka diperoleh kesepakatan untuk pembuatan kemasan oleholeh dengan kriteria yang tertentu, seperti bahan, ukuran, warna, dan desain.

Pertemuan melalui zoom meeting dilakukan karena sedang dalam kondisi pandemi covid-19, yang tidak memungkinkan melakukan tindakan tatap muka. Setelah kesepakatan tersebut, maka dilanjutkan membuat prototype kemasan, melakukan pemesanan kardus di percetakan. Dan langkah terakhir adalah melakukan penyerahan kardus untuk kemasan oleh- 
oleh kepada UMK binaan 'Aisyiyah, yang diwakili oleh bu Musofah, sebagai Ketua Ikatan Pengusaha 'Aisyiyah (IPAS) di Pujon. Jika diringkas metode yang dilakukan dalam pengabdian masyarakat ini disajikan pada Tabel 1 berikut:

Tabel 1. Metode Pengabdian yang dilakukan

\begin{tabular}{llll}
\hline \multicolumn{2}{c}{ Identifikasi Masalah } & \multicolumn{1}{c}{ Penerapan Solusi } & \multicolumn{2}{c}{ Luaran } \\
\hline Kurangnya pengetahuan dalam & Memberikan pengetahuan & Mitra memahami akan \\
pemasaran produk, khususnya & tentang pengemasan yang pentingnya kemasan yang \\
pengemasan yang menarik & menarik untuk oleh-oleh & $\begin{array}{l}\text { menarik } \\
\text { Mitra belum mengetahui dan }\end{array}$ & $\begin{array}{l}\text { Dibuatkan disain kemasan } \\
\text { Karton kemasan oleh-oleh }\end{array}$ \\
belum pernah merancang & $\begin{array}{l}\text { untuk oleh-oleh produk untuk produk olahan susu } \\
\text { kemasan produk oleh-oleh }\end{array}$ & \\
\hline
\end{tabular}

\section{HASIL DAN PEMBAHASAN}

Pelaksanaan program Pengabdian Masyarakat ini akan meningkatkan daya tarik produk oleh-oleh dari Mitra program tersebut. Sebagaimana yang dijelaskan pada analisis situasi di atas, untuk menyelesaikan masalah pada program tersebut dapat dijelaskan sebagai berikut:

1. Meningkatkan pengetahuan Mitra tentang kemasan produk oleh-oleh

Sejauh ini penjualan oleh-oleh tersebut tidak menggunakan kemasan produk secara khusus. Jika ada wisatawan yang berbelanja, maka akan diambilkan dari kios yang ada dan hanya dibungkus dengan kresek, tanpa mempertimbangkan rasa menarik ataukah tidak. Kondisi ini tentu tanpa mempertimbangkan bawaan konsumen (wisatawan) secara menyeluruh bagi dan kesulitan yang dihadapi. Kemasan yang baik adalah kemasan yang bisa memenuhi kepuasan pelanggan (client), karena mendesain kemasan bukan mempertimbangkan aspek estetika semata, tapi kemasan harus mampu memenuhi tujuan utama penciptaan kemasan tersebut (Gema et al., 2018).

Kemasan suatu produk sangat penting, apalagi jika merupakan produk oleh-oleh daerah wisata. Pakar pemasaran Kartajaya (1996) mengatakan bahwa teknologi telah membuat kemasan berubah fungsi, yaitu "kemasan sebagai protects what it sells (Kemasan melindungi apa yang dijual)". Dalam perkembangannya menjadi, "Kemasan sells what it protects (Kemasan menjual apa yang dilindungi)" (Amelia \& Oemar, 2017). Kemasan bukan lagi sebagai pelindung atau wadah tetapi harus dapat menjual produk yang dikemasnya. Kemasan yang menarik serta ramah lingkungan menambah daya tarik konsumen untuk membeli produk (Mahmud et al., 2020).

Produk yang akan dikemas dari program pengabdian ini adalah paket oleh-oleh wisata, sebagaimana hasil identifikasi melalui observasi, serta dilanjutkan dengan pertemuan zoom meeting, adalah sebagai berikut: 


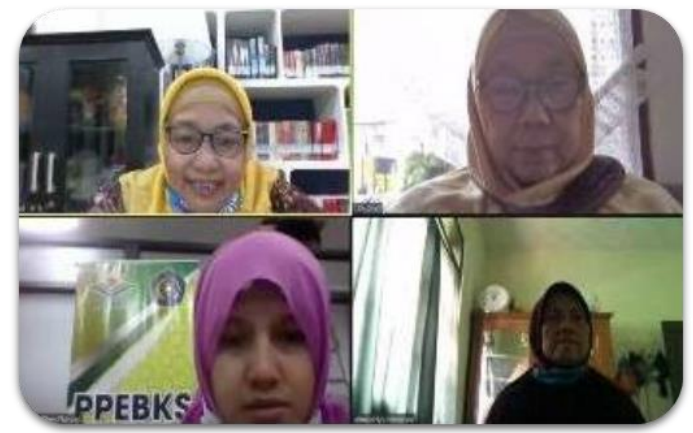

Gambar 1. Memberikan penjelasan tentang pentingnya "Kemasan Produk Oleh-oleh"

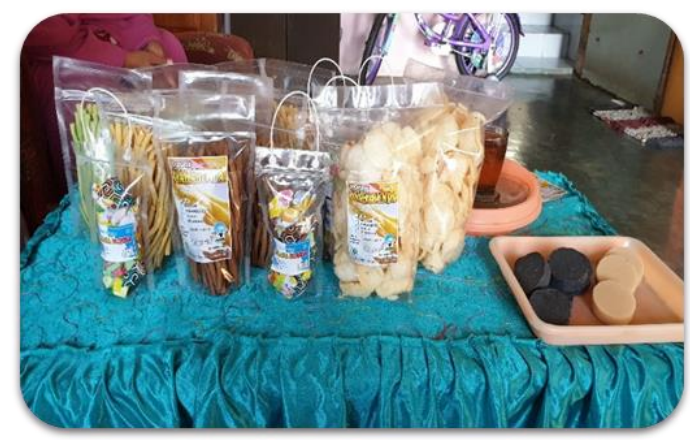

Gambar 2. Produk yang akan dikemas

\section{Oleh-oleh produk Olahan susu dikemas dalam karton yang menarik}

Pada proses selanjutnya, setelah mengidentifikasi dan menentukan jenis produk yang akan dikemas, maka ditentukan karton yang akan digunakan dalam pengemasan. Dalam membuat desain kemasan ada beberapa ketetapan yang perlu dipahami oleh desainer kemasan. Pengetahuan tersebut berkaitan dengan pengelolaan elemen verbal, elemen visual, dan invisible element. Semua elemen tersebut merupakan elemen desain kemasan yang dalam Peraturan Pemerintah disebut sebagai label (Gema et al., 2018). Oleh karena itu dilakukan pengukuran agar fungsi dari kemasan tersebut dapat terpenuhi. Adapun berdasarkan pada fungsinya kemasan modern dibagi menjadi 6 yakni: 1) Fungsi Proteksi, 2) Fungsi Pengelompokan, 3) Fungsi Keamanan, 4) Fungsi Informasi, 5) Fungsi Kemudahan Fisik, 6) Fungsi Marketing, yang diharapkan bisa memvisualisasikan "brand" alias membantu branding sebuah produk; (Purnomo et al., 2013). Adapun ukuran kemasan karton tersebut adalah Panjang $(P)=26 \mathrm{~cm}$; Lebar $(L)=20 \mathrm{~cm}$, serta Tinggi $(T)=19 \mathrm{~cm}$, Jika digambar sebagai berikut: 


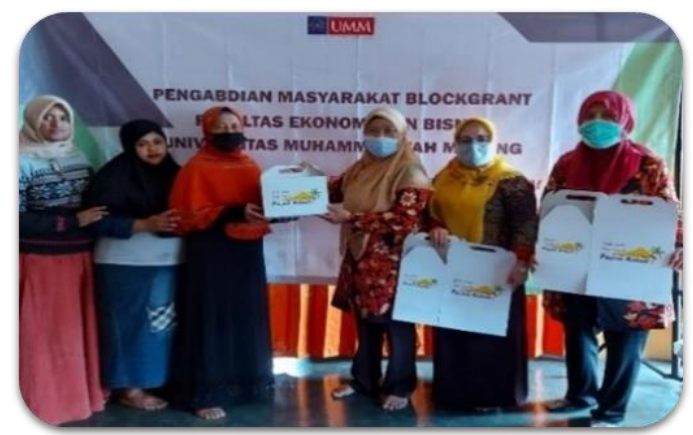

Gambar 3. Penyerahan Kemasan kepada UMK Binaan Aisiyah

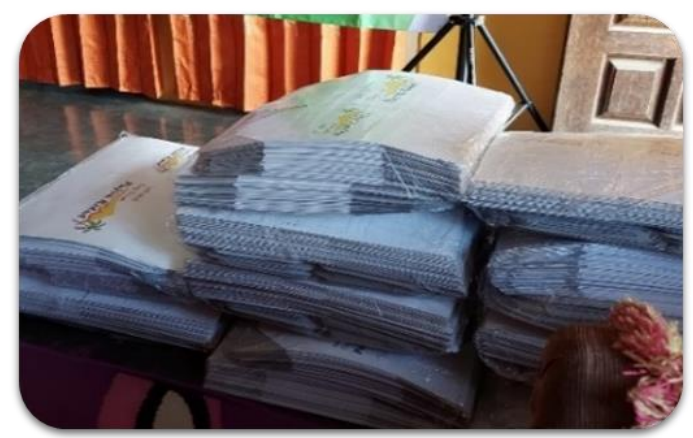

Gambar 4. Bantuan Kemasan Oleh-Oleh

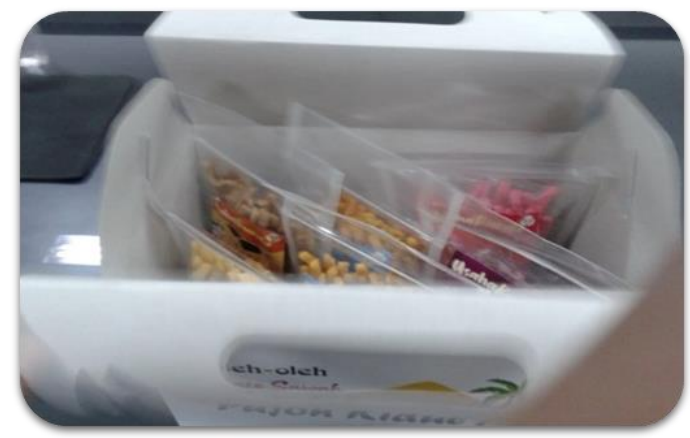

Gambar 5. Bagian Dalam Kemasan

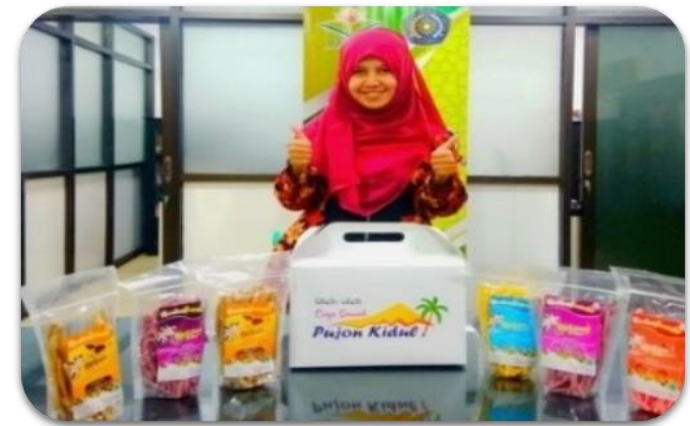

Gambar 6. Produk UKM dan Hasil Desain Kemasan 


\section{KESIMPULAN}

Fungsi utama dari kemasan adalah melindungi sebuah benda atau produk, dan seiring perkembangan saat ini, fungsi kemasan tidak hanya menjadi sebuah pelindung. Kemasan juga mampu menjadi identitas sebuah produk, dan juga sebagai promosi berantai yang efektif. Oleh karena itu diperlukan kemasan yang baik, khususnya pada produk oleh-oleh wisata, agar memiliki identitas yang kuat tidak hanya bagi produk namun juga bagi destinasi itu sendiri, serta mampu merepresentasikan citra produk yang kuat.

Kemasan oleh-oleh wisata Pujon Kidul juga bertujuan memberi kesan elegan terhadap produk, sehingga terlihat menarik dan menjadi daya tarik tersendiri bagi wisatawan. Selain itu kemasan ini juga memberi informasi, karena dapat menjadi media promosi, saat produk dibawa ke tempat baru sebagai oleh-oleh yang menjadi ciri khas wisata.

\section{UCAPAN TERIMA KASIH}

Ucapan terimakasih kepada Universitas Muhammadiyah Malang yang memberikan fasilitas dan dukungan dalam pelaksanaan Program Pengabdian kepada Masyarakat.

\section{DAFTAR RUJUKAN}

Adiyanto, O., Jatmiko, H. A., \& Erni. (2019). Development of food packaging design with kansei engineering approach. International Journal of Scientific and Technology Research, 8(12), 1778-1780.

Amelia, D., \& Oemar, E. A. (2017). Perancangan Desain Kemasan Peppy's Snack Surabaya. Jurnal Seni Rupa, 5(3), 584-590. https://jurnalmahasiswa.unesa.ac.id/index.php/va/article/view/21695

Apriyanti, E. M. (2018). Pentingnya Kemasan terhadap Penjualan Produk Perusahaan. Sosio E-Kons, 10(1), 20-27. https://doi.org/10.30998/sosioekons.v10i1.2223

Bernardo, E., \& Rodrigues, V. (2020). Buying Sweet Memories: The Heritagization of Food Souvenirs in Northern Portugal. Journal of Gastronomy and Tourism, 4(3), 129-140. https://doi.org/10.3727/216929720x15846938924003

Buku Pintar Dana Desa, Kemenkeu RI 113 (2017).

Dharmeria, V. (2014). Analisis pengaruh keunikan desain kemasan produk, kondusivitas. Jurnal Sains Pemasaran Indonesia, 13(1), 1-44. https://doi.org/10.14710/jspi.v13i1.1-44

Dumbrovská, V., \& Fialová, D. (2020). The city of one hundred souvenir shops: authenticity of souvenirs in Prague. Journal of Tourism and Cultural Change, 18(2), 187-200. https://doi.org/10.1080/14766825.2019.1606228

Gema, A. J., Sabartua, T., Priwanto, B., Triharyanto, E., Susantiningrum, S., Sutrisno, J., Firzan, M., Budiman, A., Raharjo, P. B., Kuswanto, G., Sari, D. I. D., Lee, R., Kurniawan, R. M., \& Hasin, N. (2018). Panduan Pendirian Usaha Disain Kemasan (A. L. Riani \& N. Widyamurti (eds.)). Badan Ekonomi Kreatif \& Universitas Sebelas Maret. 
Hartanti, M., Lukman, C. C., \& Nina Nurviana. (2020). Representation of Women in Food Souvenir Packaging in Bandung, Indonesia, 1950 to 2018. International Journal of Visual Design, 14(2), 1-2. https://doi.org/10.18848/2325-1581/CGP/v14i02/1-19

Huang, S. C. L., Wang, C. Y., \& Yan, Y. R. (2020). Motivational typology of online food souvenir shoppers and their travel-related intentions. Sustainability (Switzerland), 12(18). https://doi.org/10.3390/su12187624

Kidul, P. (n.d.). Desa Wisata.

Lemy, D. M., Darmawan, D., \& Tjokromulia, J. P. (2019). Food Souvenirs From Bali - What Matters for Tourists From Jakarta? Journal of Business on Hospitality and Tourism, 5(2), 298-306. https://doi.org/10.22334/jbhost.v5i2.169

Lestari, F. D., \& Sunarti. (2019). Pengaruh Motivasi Terhadap Keputusan Berkunjung (Survei Pada Pengunjung Desa Wisata Pujon Kidul Kabupaten Malang). Jurnal Administrasi Bisnis (JAB), 70(1), 29-35. http://administrasibisnis.studentjournal.ub.ac.id/index.php/jab/article/vie w/2811

Mahmud, M. Z., Widayat, \& Rahmad Wijaya. (2020). Causality Model Of Consumer Purchase Intention On Environmentally Friendly. 10(02), 36-50. https://doi.org/10.22219/jmb.v10i2.14791

Mayrowani, H. (2013). Kebijakan Penyediaan Teknologi Pascapanen Kopi dan Masalah Pengembangannya. Forum Penelitian Agro Ekonomi, 31(1), 31. https://doi.org/10.21082/fae.v31n1.2013.31-49

Mufreni, A. N. (2016). Pengaruh Desain Produk, Bentuk Kemasan Dan Bahan Kemasan Terhadap Minat Beli Konsumen (Studi Kasus Teh Hijau Serbuk Tocha). Jurnal Ekonomi Manajemen, 2(2), 48-54. https://doi.org/10.37058/jem.v2i2.313

Purbaya, A. G. (2016). Strategi Peningkatan Kesejahteraan Ekonomi Masyarakat: Kasus Pengusaha Krupuk Dan Camilan Hasil Laut di Pantai Kenjeran Lama Surabaya. Oeconomicus Journal of Economics, 1(1), 71-98. https://doi.org/10.15642/oje.2016.1.1.71-98

Purnomo, N. C., Ardana, I. G. N., \& Handoko, C. T. (2013). Perancangan Kemasan Dan Media Promosi Kue Gandjelrel Khas Kota Semarang. Jurnal DKV Adiwarna, Universitas Kristen Petra, 1(2), 1-7. http://publication.petra.ac.id/index.php/dkv/article/view/714

Purwantara, S., Hastuti, \& Khotimah, N. (2019). Pemberdayaan Perempuan Dalam Pemanfaatan Sumberdaya Perdesaan. 53(9), 1689-1699. https://doi.org/10.1017/CBO9781107415324.004

Peraturan Pemerintah 60 Tahun 2014 tentang Dana Desa, 1 (2014).

Sururi, A. (2015). Pemberdayaan Masyarakat Melalui Program Pembangunan Infrastruktur Perdesaan Dalam Meningkatkan Kesejahteraan Masyarakat Kecamatan Wanasalam Kabupaten Lebak. Jurnal Administrasi Negara, 3(2), 1-25. https://doi.org/10.30656/sawala.v3i2.229

Tandiontong, M., Carolina, V., \& Sitanggang, F. (2010). Pengaruh Biaya 
Kualitas Terhadap Tingkat Profitabilitas Perusahaan ( Studi Kasus pada The Majesty Hotel and Apartment , Bandung ). Akurat Jurnal Ilmiah Akuntansi, 2, 1-17.

Tyas, A. S. P. (2017). Identifikasi Kuliner Lokal Indonesia dalam Pembelajaran Bahasa Inggris. Jurnal Pariwisata Terapan, 1(2), 38. https://doi.org/10.22146/jpt.24970

Vicki, F. (2019, September). BUMDes picu pertumbuhan inklusif ekonomi masyarakat. AntaraNews.Com.

Wisata, D. B. I. P. 1. 73. D. (n.d.). Data BPS: Indonesia Punya 1.734 Desa Wisata. 